4 Newman $G G$, Weingarten $A E$, Abramowitz RM et al. The anesthetic management of the paticnt with an anterior mediastinal mass. Ancsthcsiology 1984; 60: 144-7.

\section{Inadequate analgesia with lumbar epidural following retroperitoneal dissection}

To the Editor:

We wish to report a problem with incomplete spread of epidural analgesia following radical retroperitoneal dissection.

Radical retroperitoneal dissection has recently been proven to be the most effective method for treating retroperitoneal malignancies, especially of testicular origin. The operative procedure involves a thoraco-abdominal exploration with en bloc removal of retroperitoneal structures up to the level of the diaphragm. Epidural analgesia has been suggested as an effective method of postoperative pain relief without compromizing pulmonary function in patients undergoing this procedure.' Many of these patients receive bleomycin therapy before surgery and may be at increased risk of developing the adult respiratory distress syndrome (ARDS) postoperatively; administration of a high $\mathrm{FlO}_{2}$ is thought to be contributory in such instances.

At our institution, we routinely employ epidural analgesia postoperatively for patients undergoing thoracoabdominal dissections. Of the 90 patients treated in this manner, satisfactory analgesia could not be achieved in nine patients. In those patients pain persisted in the upper areas of the incision despite both motor and sensory blockade in the lower abdomen and extremities and mild to moderate hypotension with each activation. Moreover, relatively large volumes of local anaesthetic solution (bupivacaine $25-30 \mathrm{ml}, 0.5$ per cent or lidocaine $15-25$ $\mathrm{ml} 1.5$ per cent solution) were used unsuccessfully in each instance, even with the patient in the Trendelenberg position. We also observed that in all nine patients the epidural catheter was placed at the $\mathrm{L}_{4}-\mathrm{L}_{5}$ interspace, and that placement of another catheter at the $L_{1}-L_{2}$ interspace with the tip directed 6 to $10 \mathrm{~cm}$ cephalad achieved satisfactory pain relief.

Anatomically, the epidural space communicates laterally with the paravertebral space through the intravertebral foramina. The paravertebral space is limited laterally and anteriorly by retroperitoneal tissue. Following radical retroperitoneal dissection, the paravertebral space communicates freely with the retroperitoneal space. ${ }^{2-6} \mathrm{We}$ suggest that epidural injection of a local anaesthetic at or below the level of the dissection results in leakage of the solution from the epidural space through the intravertebral foramina into the retroperitoneal space. Reduced retention and spread of the anaesthetic solution within the epidural space would explain the initial inadequate pain relief with the $L_{4}-L_{5}$ catheter in our nine patients. We now place epidural catheters at $\mathrm{L}_{1}-\mathrm{L}_{2}$ routinely in patients undergoing thoraco-abdominal resections, and since have had uniformly satisfactory analgesic results.

Duraiyah Thangathurai MD FFARCS

Maged Mikhail MD

David Fishmañ $M D$

University of Southern California School of Medicine

Kenneth Norris Jr Cancer Cancer Hospital and Research Institute

Los Angeles, CA.

\section{REFERENCES}

1 Bromage PR, Camporesi E, Chesinut D. Epidural narcotics for post-opcrative analgesia. Anesth Analg 1980; 59: 473-80.

2 Burn JM, Guyer PB, Langdon $L$. The spread of solutions injected into the epidural space. Br J Anaesth 1973; 45; 338-345.

3 Luyendijk $W$, van Voorthuisen $A E$. Contrast examination of the spinal epidural space. Acta Radiol 1966; 5: 1051-66.

4 Nishimura N, Kitahara T, Kusakabe T. The spread of lidocaine and 1-131 solution in the epidural space. Anaesthesiology 1959; 20: 785.

5 Husemeyer RP, White DC. Lumbar extradural injection pressures in pregnant women. $\mathrm{Br} \mathrm{J}$ Anaesth 1980; 52: 55-60.

6 Macintosh RR, Mushin WW. Observations on the epidural space. Anaesthesia 1947; 2: 100.

\section{Measurement of gastric contents}

To the Editor:

We agree with the conclusion of Taylor et al.' that blind aspiration of gastric contents gives a fair estimate of volume, even if this is always an underestimate (the same may be true of dye dilution techniques). ${ }^{2}$ One cannot determine from their data whether all of the additional volume obtained under direct vision with a gastroscope remained in the stomach following the initial blind aspiration, or represented endogenous secretions in response to the Salem sump tube and the gastroscopy 
procedure. Either tube could stimulate secretion by mechanical irritation of the gastric mucosa - this was how Beaumont sometimes obtained gastric juice from Alexis St Martin's stomach 150 years ago for in vitro experiments. ${ }^{3}$ Similarly, endogenous gastric secretions may be stimulated by insufflation of air during gastroscopy. The latter manipulation may also allow duodenogastric reflux to occur; no comment was made concerning bile-staining or $\mathrm{pH}$ value of the additional volume obtained after the initial, blind aspiration. The difference in volumes would have been more convincing if gastroscopy had been performed first in half the patients, and if the initial volume had been returned to the stomach before remeasurement using the alternative technique.

How important is absolute versus readily aspirated volume? Irrespective of the measuring technique, the variation from one patient to another is large. This occurs in patients who fast from midnight, those who ingest fluid 2-3 hr preoperatively, and in those who do or do not take an $\mathrm{H}_{2}$ receptor blocker or other medication. ${ }^{4}$ Comparisons among large groups using the same sampling techniques are more important than precise measurements because we do not know the precise volume of gastric juice in the stomach required to cause pulmonary acid aspiration syndrome. The often-quoted $25 \mathrm{ml}$ and $\mathrm{pH} 2.5$ was derived by Shirley and Roberts from unpublished rhesus monkey experiments, ${ }^{5}$ and was the "maximum acid aspirate that does not produce significant changes in the lung." That volume was the volume injected into the lungs, not the volume which was in the stomach. This important fact is overlooked by those who claim that 25 $\mathrm{ml}$ in the stomach represents "high risk for pulmonary aspiration." If regurgitation occurs, does $25 \mathrm{ml}$ gastric contents equal $25 \mathrm{ml}$ in the lungs? It is unlikely that every drop of gastric fluid leaves the stomach, and some pooling may occur in the pharynx. This could explain why although 40 per cent of elective patients are designated "high risk," the incidence of clinically significant pulmonary aspiration is nearer 1 in 10,000 in elective inpatients, ard death is extremely rare. ${ }^{6}$

\section{J. Roger Maltby MB BChir, FFARCS FRCPC \\ Department of Anaesthesia \\ Eldon A. Shaffer MD FRCPC FACP}

Division of Gastroenterology, Department of Medicine Foothills Hospital at the University of Calgary 140329 Street NW

Calgary, Alberta T2N 2T9

\section{REFERENCES}

1 Taylor WJ, Barry AW. Measuring gastric contents during general anaesthesia: evaluation of blind gastric aspiration. Can J Anacsth 1989; 36: 1-4.
2 Hardy JF, Plourde G, Lebrun M, Cote C, Dube S, Lepage $Y$. Determining gastric contents during general anaesthesia: evaluation of two methods. Can J Anacsth 1987; 34: 474-7.

3 Beaumont $W$. Experiments and observations on the gastric juice and the physiology of digestion. Plattsburgh 1833 : 134-5.

4 Maltby JR, Koehli, Ewen A, Shaffer EA. Gastric fluid volume, $\mathrm{pH}$, and emptying in elective patients. Influences of narcotic-atropine premedication, oral fluid, and ranitidine. Can J Anaesth 1988; 35: 562-6.

5 Roberts RB, Shirley $M A$. Reducing the risk of aspiration during cesarcan section. Anesth Analg 1974; 53: 859-68.

6 Hardy JF. Large volume gastroesophageal reflux: a rationalc for risk reduction in the perioperative period. Can J Anaesth 1988; 35: 162-73.

\section{Sir Robert Macintosh}

To the Editor:

The recent death of Sir Robert Macintosh reminds us of the contributions of US and UK Universities to Canadian and worldwide anaesthesia. In 1947 Dr. Stewart Cullen, then of lowa city, demonstrated "balanced anaesthesia" to an astonished group of surgeons at the University of Innsbruck, Tyrol, Austria. One of them, Dr. Bruno Haid, was so impressed that he took up anaesthesia and trained with Dr. Cullen. In 1959, Dr. Haid became the first professor of anaesthesia of an independent department in continental Europe in Innsbruck. Its 30th anniversary was recently celebrated at the 21 st Central European Congress in Innsbruck. An impressive Festschrift was published which contained a letter from Dr. Macintosh in which he recounted how he helped to persuade the Government and the University to establish an independent anaesthesia department. One of Professor Macintosh's first assistants in Oxford was Dr. James Parkhouse, who became the first professor of an independent department at the University of Manitoba in 1967. At that time, Dr. Cullen had trained seven Canadians who all stayed in Manitoba, two becoming Heads and one (Dr. John Wade) a Dean.

This letter is written by a native of Innsbruck who trained in London and New York.

Christopher Wolkenstein MB FRCP

Associate Professor of Anaesthesia University of Manitoba (ret.) 